\title{
Internalizing externalities of loss prevention through insurance monopoly: an analysis of interdependent risks
}

\author{
Annette Hofmann
}

Received: 15 February 2006/Revised: 15 November 2006/Published online: 10 July 2007

(C) The Geneva Association 2007

\begin{abstract}
When risks are interdependent, an agent's decision to self-protect affects the loss probabilities faced by others. Due to these externalities, economic agents invest too little in prevention relative to the socially efficient level by ignoring marginal external costs or benefits conferred on others. This paper analyzes an insurance market with externalities of loss prevention. It is shown in a model with heterogenous agents and imperfect information that a monopolistic insurer can achieve the social optimum by engaging in premium discrimination. An insurance monopoly reduces not only costs of risk selection, but may also play an important social role in loss prevention.
\end{abstract}

Keywords Externalities · Insurance monopoly · Nash equilibrium · Social welfare

JEL Classification $\quad \mathrm{C} 70 \cdot \mathrm{D} 62 \cdot \mathrm{G} 22$

\section{Introduction}

Wealth is subject to possible loss, and therefore rational agents (private firms or individuals) desire to invest in loss prevention activities that reduce the probability of loss. ${ }^{1}$ An interesting feature of individual loss prevention is that

\footnotetext{
1 In the literature, loss prevention is often called "self-protection" to mean a reduction in the probability of loss without affecting the magnitude of loss, while loss reduction is called "self-insurance" which means a reduction in the magnitude of loss without affecting the probability of loss. This distinction was originally introduced by Ehrlich and Becker [1972].
}

A. Hofmann $(\square)$

Institute for Risk and Insurance, University of Hamburg, Hamburg, Germany

e-mail: ahofmann@econ.uni-hamburg.de 
it may affect the risks faced by others. In many cases of individual investment decisions, the ultimate risk of each decision-maker depends in some way on the aggregate actions of others. The risks are interdependent. The individual risk can then be broken down into direct and indirect sources. The direct risk arises due to an agent's own actions, and can be reduced or eliminated by an investment in prevention. The indirect risk lies entirely in the hands of other agents. A great variety of problems share such risk interdependencies. As an illustration, consider the following examples.

\subsection{Airline baggage security}

Due to the network structure of (inter-)national flights, the security at one airport may have impacts on the security at other airports. More specifically, the risk that an aircraft of an airline, say, airline $A$, is harmed by an explosive device on board, depends not only on its own security system, but also on the fact that other airlines, say $B, C$ etc., screen luggage items that are transferred into an aircraft of $A$, too. In general, luggage items transferred between aircrafts are almost never screened, for reasons of cost and timing. One trusts, in fact, that these luggage items were already screened at their departure terminal. The acquisition of a safety system by $A$ can therefore only eliminate the risk of damage resulting from directly boarding passengers. The risk that dangerous luggage is transferred from other aircrafts cannot be excluded in this way. This indirect risk depends on the security systems at other airports. ${ }^{2}$

\subsection{Shared computer resources}

Suppose an owner of a small business has a desktop computer with its own software and memory, but also keeps his largest and most important data files on a hard disk drive that is shared with many others. If a virus or other piece of malicious software enters the user network (e.g., via email of another user), it may erase the contents of the shared hard drive, and thus cause loss of profit due to business interruption. The safety of the shared hard drive depends on the diligence of all users whose desktop computers present potential points of contamination. Therefore, a single user's incentive to invest in loss prevention (e.g., anti-virus software, firewalls, spamfilters, etc.) is interdependent with the actions of other users in the community. Then, a user's direct risk is the risk that the hard drive will be erased by malicious software entering the system through his own desktop computer, while the remaining indirect risk is the risk that the hard drive will be erased by malicious software entering the system through someone else's computer. He can reduce or eliminate the first risk by investing in prevention, but cannot influence the latter. ${ }^{3}$

\footnotetext{
${ }^{2}$ This problem of interdependent security was first analyzed by Kunreuther and Heal [2003] in a gametheoretic framework. Note the empirical relevance by recalling the events of September 11, 2001, where security failures at airports in Boston, New Jersey, and Washington DC led to crashes at the World Trade Center and in Pennsylvania.

3 See Kearns [2005, pp. 40-47].
} 
Similar effects result, for instance, with investments in prevention relating to certain catastrophe, health or liability risks. A company's mounting of a sprinkler system decreases the risk of fire for the neighboring companies. A farming business that utilizes certain hazardous substances also influences the risks of surrounding farms (i.e., through changes in genetic pools, etc.). Many health risks are imposed by others. A common example is smokers creating cancer risks also for nonsmokers via passive smoke, known as the second-hand smoking problem. ${ }^{4}$ Any individual investment to stop smoking benefits non-smokers as well, and hence such investment generates an externality. Risks of traffic accidents are interdependent, as well. Here, the direct risk is the risk that a careless driver causes an accident himself, the indirect risk is the risk that the driver is involved in an accident caused by someone else. He can only reduce the first risk by driving more cautiously, but he can do nothing about the second one. However, careful driving behavior diminishes the indirect risk for others. 5

In many individual decision problems, as in the examples above, the possible loss cannot be avoided completely by a preventive investment. A residual (indirect) risk remains. This risk depends on the behavior of other agents. In general, those who invest in loss prevention incur some cost (i.e., discomfort, time or money) and, in return, receive some individual benefit through the reduced individual expected loss, but a part of the benefit is public: the reduced indirect risk in the economy from which everybody else benefits. Hence, there is a negative externality associated with not investing in loss prevention, i.e., the increased risk to others. A well-known result in public economics suggests that when externalities are present, equilibrium behavior is inefficient. In our setting of interdependent risks, this means the total level of preventive activities in the economy will be "too low" relative to the socially efficient level. Therefore, a resulting risk allocation will not be efficient. The challenge is to find a solution to the allocation problem. ${ }^{6}$

When agents face interdependent risks, it may be possible to internalize the externalities by encouraging the agents to individually self-protect through a set of economic incentives that makes it more attractive for some agents to invest in loss prevention. Insurance alters economic incentives, and for that reason this allocation problem may be solved in an insurance market. Externalities may be internalized within a compulsory insurance monopoly. However, compulsory insurance monopolies present a considerable intervention into the freedom of choice of individuals and firms. Therefore, a particular justification should be given that a compulsory insurance monopoly may lead to a higher social level of loss prevention and, in this way, may increase allocative efficiency. The rationale is that prevention

\footnotetext{
${ }^{4}$ See Lee [2005, p. 156].

5 Some further examples of interdependent risks are provided by Avery et al. [1995].

${ }^{6}$ Clearly, the allocation problem would not arise if economic agents had the possibility to carry out free negotiations and to conclude binding contracts (given a world with perfect information and without transaction costs). Then those damaged by externalities would pay the liable party a compensation for undertaking preventive measures. Free negotiations then lead to the Pareto-optimal prevention level. See Coase [1960]. Mathematical proof on this can be found in Gifford and Stone [1973].
} 
externalities lead to a market failure, and this market failure may be corrected by a compulsory insurance monopoly. ${ }^{7}$

Epple and Schäfer [1996] and Felder [1996] study the efficiency of compulsory insurance monopolies compared to competitive insurance markets empirically for Germany, while Jametti and Ungern-Sternberg [2005] and Ungern-Sternberg [1996, 2003, 2004] consider Switzerland and other European countries. ${ }^{8,9}$ The studies find that insurance monopolies are more efficient than private providers (i.e., claims levels are lower), and suggest that a market with a state-monopoly for insurance leads to a remarkably higher level of social loss prevention than private markets. Why can insurance monopolies in practice lead to a remarkably higher social level of loss prevention? Ungern-Sternberg [2004] attributes the efficiency of monopolies to their potential to internalize prevention externalities. ${ }^{10}$ This issue has not yet been addressed theoretically. The present paper suggests a theoretical explanation.

Incentive problems associated with externalities have been analyzed theoretically in the insurance literature. Externalities of loss prevention have been studied, though in a different context, by Shavell [1982] who focuses on how liability rules and insurance affect incentives to reduce accident risks and the allocation of such risks. Shavell [1979], Arnott and Stiglitz [1986], and Bond and Crocker [1991] consider

\footnotetext{
${ }^{7}$ A further argument may be that, if insurance were not compulsory, there might possibly be insufficient demand for insurance coverage. In the case of terrorism or natural hazard insurance, for example, agents may anticipate financial relief from the government in case of loss. In fact, a government cannot afforddue to political and social reasons-to leave victims of terrorism or natural catastrophes such as floods or earthquakes uncompensated. Therefore, public programs making relief to victims contingent on individual prevention investments cannot be considered credible. The agents tend to free-ride by not investing (enough) in loss prevention, and trust in government relief in case of loss. Government relief therefore distorts private incentives. A market failure results that may be solved by compulsory insurance. See, for example, Kaplow [1991]. In Spain, for instance, the free-rider problem is solved by a state-run insurance monopoly for natural catastrophe risks. See, for instance, Ungern-Sternberg [2004, pp. 56-74].

${ }^{8}$ This efficiency can be studied particularly well in Switzerland due to the Swiss dual system in property insurance. In 19 of the 26 Swiss cantons, house owners are required by law to obtain coverage for natural catastrophes and fire from cantonal insurance providers. This coverage is only available with private insurance companies in the remaining seven cantons. The cantonal insurance monopolies are found to be more efficient than private providers. Claims levels are lower and there is a higher social investment in loss prevention. Cantonal insurance monopolies earn a low or zero rate of return, insurance premiums are regulated on a cantonal basis, and the creation of a minimum reserve is required by law.

${ }^{9}$ In general, loss prevention activities in a society can be of collective or individual nature. For example, collective measures target at general fire-protection or the mitigation of flood risks in certain exposed areas. In the case of an investment in collective prevention by the insurer, compulsory insurance is important in order to induce the monopolist to undertake those investments. Note that without compulsory insurance, if the monopolist could manipulate loss probabilities by an investment in collective loss prevention, one option of an agent would be to enjoy the lower loss probability, but not to purchase any insurance coverage. Hence, a key feature of an investment in collective prevention by the insurer is the nonexcludability of agents who choose not to purchase insurance from also experiencing the reduction in loss probability. See Schlesinger and Venezian [1986]. However, a large part of preventive activities is individual in nature. These measures are individual investments that target at the reduction of individual expected loss. We focus on preventive activities of individual nature in this paper. Therefore, the insurer's premiums should be calculated to motivate the policyholders to individually invest in loss prevention. From the insurer's viewpoint, this makes perfect economic sense because it benefits from a higher social prevention level (resulting in lower expected claims payments). Thus the insurer has an economic reason to subsidize preventive activities in the economy.
}

${ }^{10}$ See Ungern-Sternberg [2004, pp. 112-113]. 
insurance market externalities induced by moral hazard. Shavell [1979] addresses agents' incentives to underconsume "care," which reduces the probability of loss. He finds that second-best contracts including deductibles lower those incentives, so that agents bear part of the risk resulting from their decisions regarding "care" themselves. Arnott and Stiglitz [1986] derive an optimal commodity taxation system. They find that when agents purchase hazardous goods, taxing those goods that are complementary and subsidizing those that are substitutable for loss prevention activities affects the agents' consumption decisions. Bond and Crocker [1991] analyze the effects on efficiency and equilibrium when consumers purchase products that are correlated with underlying loss propensities in an environment exhibiting both moral hazard and adverse selection. They show that categorization may permit first-best allocations as competitive Nash equilibria. In contrast to this paper, Bond and Crocker are concerned with the insurance market externality resulting from the increased probability of loss by the purchaser, as opposed to any direct effects on third parties. Most of these models consider homogeneous agents or a representative individual.

The purpose of the present paper is threefold. First, we study economic incentives to invest in loss prevention for heterogeneous risk-averse agents in a model with interdependent risks. We intend to find a solution to the above described allocation problem. Interdependencies of risks are modeled following Kunreuther and Heal [2003]. ${ }^{11}$ Second, we implement the concept of interdependent risks to insurance markets and demonstrate that a monopolistic insurer with imperfect information can achieve the socially optimal prevention level by engaging in premium discrimination. ${ }^{12}$ Finally, we offer a theoretical explanation of empirical findings; in particular, we explain why the social prevention level in markets with (compulsory) insurance monopolies tend to be substantially higher than in competitive insurance markets.

The paper proceeds as follows. The next section introduces the formal model in an expected utility framework. We begin by analyzing the simplest case of two homogeneous agents. Then we introduce multiple agents and heterogeneity. The following section characterizes the Nash equilibrium, first when insurance is not available, then with insurance at actuarially fair premiums. Finally, it is shown that, given compulsory insurance, a monopolistic insurer can achieve the social optimum

\footnotetext{
${ }^{11}$ Kunreuther and Heal [2003] have analyzed the interdependencies of terrorism risks in the context of international airline security for identical and risk neutral agents. They expanded their work to a more general model of interdependent risks in Heal and Kunreuther [2004]. In the general model, three classes of problems of Interdependent Security (IDS) are derived: a Class 1 problem [Partial Protection], a Class 2 problem [Complete Protection], and a Class 3 problem [Positive Externalities]. In an IDS-problem of the first class, the risk of loss cannot be completely eliminated by an investment in security, there remains a residual indirect risk from others. This situation is the one illustrated in our examples. An example for a class 2 problem is a market for vaccination. This is characterized by the fact that the risk of loss can be completely eliminated by an investment in protection, the vaccine. In an IDS-problem of the third class, positive externalities arise. An example is investments in research and development. This paper focuses on an IDS-problem of the first class which seems to be the most important. However, the model can be applied to other IDS-problems.

${ }^{12}$ In an insurance market with different risk types, an insurer often uses observable or known criteria that may be related to the underlying risk in order to sort the policyholders in categories for which different policies are sold. This categorization is often referred to as "discrimination."
} 


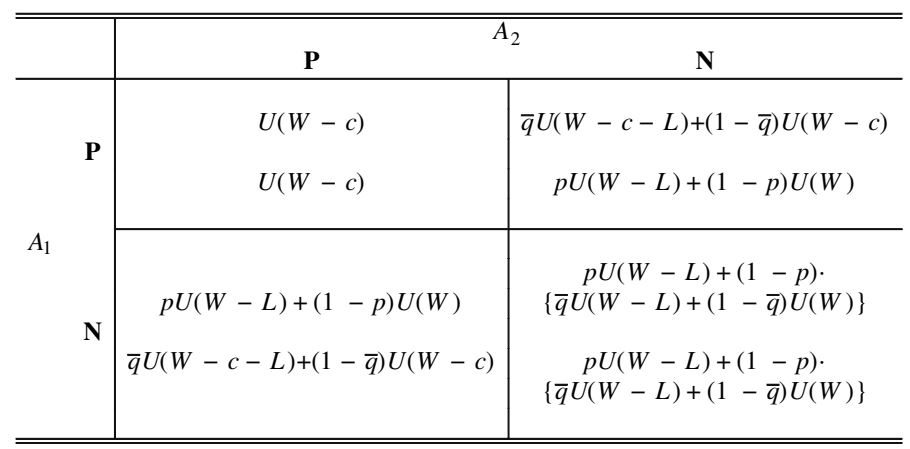

Fig. 1 Payoff matrix of expected utilities in a two-agent game

by engaging in premium discrimination and relying on the agents' self-categorization. A discussion and some concluding remarks follow.

\section{A model of interdependent risks}

Consider an economy in which each economic agent is endowed with an initial wealth, $W$, and faces a potential loss, $L$. An agent's utility $U(y)$ is a function of final wealth $y$. The utility function is twice continuously differentiable, increasing and strictly concave, i.e., agents are risk-averse. The agents maximize their expected utility of final wealth.

The agents have to decide whether or not to invest in loss prevention. This decision is a discrete choice: an agent either invests or not. Let there be two possible ways in which a loss can occur: it can either be caused directly by an agent himself (direct loss), or indirectly via the actions of others (indirect loss). Losses are not additive. ${ }^{13}$ The cost of investing in prevention is $c$. A direct loss can be avoided with certainty by an investment in prevention. We assume $W>c+L>0$. Prevention costs should not exceed the possible loss, hence $0 \leq c \leq L$. Four possible states of final wealth of an agent result: without prevention, the final wealth of an agent is $y_{1}=W$ in case of no loss, and $y_{2}=W-L$ in case of loss. If an agent invests in prevention, his final wealth is $y_{3}=W-c$ in case of no loss and $y_{4}=W-c-L$ in case of loss.

The probability of a direct loss is $p$. $p$ satisfies $0<p<1$. The probability that a loss is caused indirectly by the actions of others is $q(x)$, where $x$ denotes the proportion of agents in the economy without loss prevention. $x$ satisfies $0 \leq x \leq 1$. In general, the higher the proportion of agents without prevention in the economy, the higher will be the indirect risk. We assume $q^{\prime}(x)>0$ and $q^{\prime \prime}(x) \geq 0$. $q(x)$ satisfies $0 \leq q(x) \leq \bar{q}$, where $q(1)=\bar{q}<1$ and $q(0)=0$. These assumptions may be interpreted as follows. If nobody invests in prevention $(x=1)$, then $\bar{q}$ will denote the

\footnotetext{
13 A loss can only occur once. The maximum loss is $L$, even if both possible causes of loss occur at the same time. See also Heal and Kunreuther [2004].
} 
maximum indirect risk; this risk will generally be smaller than one. In contrast, if everybody invests in prevention $(x=0)$, then the indirect risk in the economy will be zero. $^{14}$

The events "a loss is caused directly by an agent" $(d)$ and "a loss is caused indirectly via others" ( $a$ ) are assumed to be independent. The probability of "cause of loss occurs, in case of no prevention is then $\operatorname{Pr}(d)+\operatorname{Pr}(a)-\operatorname{Pr}(d \cap a)=p+q(x)-p q(x)=p+(1-p) q(x)$. In case of prevention, this probability is reduced to $q(x)$.

\subsection{Interdependent risks for two agents}

The simplest situation of interdependent risks, involving only two agents, can be illustrated in a game-theoretic framework. The payoff matrix of expected utilities for agents $A_{1}$ and $A_{2}$ is shown in Fig. $1 .^{15}$

Suppose both agents are identical. In case of no prevention, let $q(x)=\bar{q}$ since there are only two parties involved. If both invest in prevention, the expected utility of each agent is $U(W-c)$. If $A_{1}$ invests in prevention (P) but not $A_{2}(\mathbf{N}), A_{1}$ is only exposed to the indirect risk $\bar{q}$ from $A_{2}$. Thus the expected utility of $A_{1}$ is $\bar{q} U(W-c-L)+(1-\bar{q}) U(W-c)$. The expected utility of $A_{2}$ is then $p U(W-L)+(1-p) U(W)$. If $A_{2}$ invests in prevention, but not $A_{1}$, we get the symmetrical result. If neither agent invests in prevention, then both are exposed to the additional risk of contamination from the other. Therefore, the expected utilities for both agents are $p U(W-L)+(1-p) \cdot\{\bar{q} U(W-L)+(1-\bar{q}) U(W)\}$. This is $(\mathbf{N}, \mathbf{N})$ in Fig. 1.

Assuming that both agents decide simultaneously whether or not to invest in prevention, there is no possibility to cooperate. For $\mathbf{P}$ to be a dominant strategy for $A_{1}$, we need ${ }^{16}$

$$
U(W-c) \geq p U(W-L)+(1-p) U(W) .
$$

(1) simply means that we must have $c \leq p L+\pi[p]$, where $\pi[p]$ denotes the risk premium when the loss probability equals $p .{ }^{17}$ The prevention cost must be less than the sum of expected direct loss and risk premium. In addition, we need

\footnotetext{
${ }^{14}$ Referring to the airline baggage security example, the probabilities $p$ and $q(x)$ can be understood as follows. $p$ is the probability of damage arising on an agent's (airline's) own property (aircraft) if the agent has not invested in security (direct loss). The expected loss from this event is $p L$. If the agent has invested in a security system this risk is zero. The probability that a bag containing a bomb and accepted for carriage by one airline is transferred by it to another is $q(x)$. See Kunreuther and Heal [2002, 2003].

15 This section follows Kunreuther and Heal [2003]. The novelty is the introduction of risk aversion.

16 If $A_{1}$ is indifferent between $\mathbf{N}$ and $\mathbf{P}$, we assume that he invests in prevention. It suffices to investigate the dominance of a strategy for $A_{1}$, since the situation is symmetric for both agents.

17 The risk premium, as we use it here, was introduced by Pratt [1964]. For any concave utility function $U(\cdot)$, the risk premium $\pi[p]$ is defined by the equation $p U(W-L)+(1-p) U(W)=$ $U(W-p L-\pi[p])$. The risk premium $\pi[p]$ denotes the maximum an agent is willing to pay to securely receive the expected value of the probability distribution instead of the probability distribution itself.
} 


$$
\begin{gathered}
\bar{q} U(W-c-L)+(1-\bar{q}) U(W-c) \\
\geq p U(W-L)+(1-p)\{\bar{q} U(W-L)+(1-\bar{q}) U(W)\},
\end{gathered}
$$

so that $c \leq p(1-\bar{q}) L+\pi[p+(1-p) \bar{q}]-\pi[\bar{q}]$. This (tighter) inequality reflects the possibility of damage caused by the other agent. Therefore, the Nash equilibrium is $(\mathbf{P}, \mathbf{P})$ if $c \leq p(1-\bar{q}) L+\pi[p+(1-p) \bar{q}]-\pi[\bar{q}]$. In contrast, if $c>p L+\pi[p]$, the resulting Nash equilibrium is $(\mathbf{N}, \mathbf{N})$. If $p(1-\bar{q}) L+\pi[p+(1-p) \bar{q}]-$ $\pi[\bar{q}]<c \leq p L+\pi[p]$, both equilibria are possible and the solution to the game is indeterminate. $^{18}$

Thus for $c \leq p(1-\bar{q}) L+\pi[p+(1-p) \bar{q}]-\pi[\bar{q}]$, the equilibrium (P,P) is preferable to the other possible equilibria. If social welfare of the agents is interpreted as the sum of their individual expected utilities, then the optimal social solution will indeed be achieved for $c \leq p(1-\bar{q}) L+\pi[p+(1-p) \bar{q}]-\pi[\bar{q}]$. In the case of identical agents, we have thus found two possible solutions to the game: either all agents invest in prevention or no one does. In order to find a more general solution, we introduce multiple heterogeneous agents by assuming different prevention costs in the next section.

\subsection{Interdependent risks for a continuum of agents}

Let there be a continuum of heterogeneous risk-averse agents. Agents differ only in prevention cost. ${ }^{19}$ Agents with "low" cost will tend to invest in prevention, while those with "high" cost will not. The agents can be listed in ascending order according to their individual cost $c$. The total number of agents in the economy is normalized to unity. Prevention costs are distributed with the (nondegenerate) distribution function $F(c)$ and density function $f(c)$, defined over the support $[0, L]$. The agents are free to choose whether or not to invest in loss prevention. The expected utility of an agent who does not invest in loss prevention is

$$
V(x)=p U(W-L)+(1-p)\{q(x) U(W-L)+(1-q(x)) U(W)\},
$$

while the expected utility of an agent who invests in prevention at individual cost $c$ is given by

$$
R(x, c)=q(x) U(W-c-L)+(1-q(x)) U(W-c) .
$$

Generally, an agent will invest in loss prevention if the excess of expected utility with a preventive investment over the expected utility without such an investment is

\footnotetext{
${ }^{18}$ We assume here that $p(1-\bar{q}) L+\pi[p+(1-p) \bar{q}]-\pi[\bar{q}]$ is smaller than $p L+\pi[p]$ and therefore represents a tighter inequality. This seems to be true in most cases. However, if $p(1-\bar{q}) L+\pi[p+(1-p) \bar{q}]-\pi[\bar{q}]$ exceeds $p L+\pi[p]$, the equilibria would be reversed, but there would still be only two equilibria.

19 Alternatively, it could be assumed that the agents have different prevention technologies. They can avoid a direct loss by using such a technology. Different technologies cause different costs.
} 
non-negative: $\Psi(x, c)=R(x, c)-V(x) \geq 0 .{ }^{20}$ For any given $x$, we have $\Psi(x, 0)>0$ and $\Psi(x, L)<0$.

To find the equilibrium, define the excess of expected utility to the marginal agent as $\Psi(x(\widehat{c}), \widehat{c}) \equiv \Psi(\widehat{c})$ so that

$$
\Psi(\widehat{c})=R(\widehat{c})-V(\widehat{c})
$$

with

$$
R(\widehat{c})=q(x(\widehat{c})) U(W-\widehat{c}-L)+(1-q(x(\widehat{c}))) U(W-\widehat{c})
$$

and

$$
V(\widehat{c})=p U(W-L)+(1-p)\{q(x(\widehat{c})) U(W-L)+(1-q(x(\widehat{c}))) U(W)\},
$$

where $x(\widehat{c})$ denotes the proportion of agents without prevention in the economy given that the marginal agent has a cost $\widehat{c}$ :

$$
x(\widehat{c})=\int_{\widehat{c}}^{L} f(c) d c=1-F(\widehat{c}) .
$$

$d x(\widehat{c}) / d \widehat{c}=-f(\widehat{c})<0$, i.e., the proportion of agents without prevention is strictly decreasing in $\widehat{c}{ }^{21}$ To simplify notation, we will write the functions $V(x(\widehat{c}))$, $R(c, x(\widehat{c}))$ and $q(x(\widehat{c}))$ in the following as functions of $c$ and $\widehat{c}$, respectively. Along with $0 \leq q(\widehat{c}) \leq \bar{q}<1$, it follows that

(1) at position $\widehat{c}=0$

$$
\Psi(0)=p(1-\bar{q}) \cdot\{U(W)-U(W-L)\}>0,
$$

(2) at position $\widehat{c}=L$

$$
\Psi(L)=(1-p)\{U(W-L)-U(W)\}<0,
$$

so that (1) if nobody invests in prevention and therefore the indirect risk is very high, it is worth to undertake preventive measures to reduce expected loss when prevention is costless, while (2) if everybody invests in prevention and therefore the indirect risk is zero, then an investment in prevention that is extremely costly $(L)$ is not worth being undertaken to avoid the expected direct loss $p L$.

(9) and (10) ensure that there exists an interior solution $c^{*}$, where $0<c^{*}<L$, that satisfies

\footnotetext{
${ }^{20}$ Without loss of generality, we assume that an agent invests in prevention when he is indifferent between investing and not investing.

21 Externalities have been analyzed in a similar way by Brito et al. [1991] who investigate a market for vaccination against infectious diseases. Their model refers to Mirrlees' conclusions of optimal taxation. See Mirrlees [1971].
} 


$$
\Psi\left(c^{*}\right)=R\left(c^{*}\right)-V\left(c^{*}\right)=0 .
$$

Hence, the excess of expected utility is positive for $c<c^{*}$ and negative for $c>c^{*}$, so that "low cost" agents with $c \leq c^{*}$ invest in loss prevention while "high cost" agents with $c>c^{*}$ do not. ${ }^{22}$ The competitive Nash equilibrium is then given by

$$
\begin{gathered}
U\left(W-c^{*}-q\left(c^{*}\right) L-\pi\left[q\left(c^{*}\right)\right]\right) \\
=U\left(W-\left\{p+(1-p) q\left(c^{*}\right)\right\} L-\pi\left[p+(1-p) q\left(c^{*}\right)\right]\right)
\end{gathered}
$$

$\Rightarrow$

$$
c^{*}=p\left(1-q\left(c^{*}\right)\right) L+\pi\left[p+(1-p) q\left(c^{*}\right)\right]-\pi\left[q\left(c^{*}\right)\right] .
$$

The Nash equilibrium $c^{*}$ divides all agents into two groups: those who do invest in loss prevention and those who don't. Note that the Nash equilibrium is similar to the introductory 2-agents equilibrium: all agents with a cost $c \leq c^{*}$ invest in loss prevention.

Let social welfare be represented by the utilitarian social welfare function $S(\widehat{c})$, the "sum" of the individual expected utilities of all agents. The socially optimal prevention level in the economy is the level that maximizes the welfare function. Social welfare $S(\widehat{c}) \geq 0$ is then given by

$$
S(\widehat{c})=\int_{0}^{\widehat{c}} R(c, \widehat{c}) f(c) d c+V(\widehat{c}) \cdot x(\widehat{c}) .
$$

The first term in (14) denotes the expected utilities of all agents who invest in prevention, the second the expected utilities of all agents who do not invest in prevention. The first-order condition for an interior maximum of $S(\widehat{c})$ is

$$
\begin{gathered}
\frac{d S(\widehat{c})}{d \widehat{c}}=R(\widehat{c}, \widehat{c}) \cdot f(\widehat{c})+V(\widehat{c}) \cdot \frac{d x(\widehat{c})}{d \widehat{c}}+\frac{d V(\widehat{c})}{d \widehat{c}} x(\widehat{c})+\int_{0}^{\widehat{c}} \frac{\partial R(c, \widehat{c})}{\partial \widehat{c}} f(c) d c \\
=\{R(\widehat{c}, \widehat{c})-V(\widehat{c})\} \cdot f(\widehat{c})+\frac{d V(\widehat{c})}{d \widehat{c}} x(\widehat{c})+\int_{0}^{\widehat{c}} \frac{\partial R(c, \widehat{c})}{\partial \widehat{c}} f(c) d c=0 .
\end{gathered}
$$

The second and third term in (15) are non-negative (and non-decreasing in $x$ due to $q^{\prime \prime}(x) \geq 0$ ). The first term in brackets is simply the excess of expected utility

\footnotetext{
$\overline{22}$ It cannot be shown in general that the interior solution is unique for all possible parameters in $\Psi(\widehat{c})$. In the more interesting case with insurance (see the next section), a sufficient condition for a strict monotonic relationship between the excess of expected utility and the threshold prevention cost $\widehat{c}$ is $-q^{\prime}(\widehat{c}) L \leq 1$. Since the indirect risk in the economy influences the impact of the direct risk $p$ on individual loss prevention, the marginal return of loss prevention should not be too high. However, this condition is for technical reasons only. In reasonable numerical examples, a unique equilibrium always results. Finally, the case in which there might be more than one interior solutions makes no economic sense and is therefore not relevant throughout the paper. We thus consider only the relevant monotonic cases.
} 
$\Psi(\widehat{c})$. As a consequence, given $f(\widehat{c})>0, S(\widehat{c})$ has an interior maximum at $c^{* *}$, defined by (15) so that

$$
c^{* *}=\arg \max _{\widehat{c}} S(\widehat{c}) .
$$

$c^{* *}$ is the socially optimal prevention level. ${ }^{23}$ Consider now the marginal social welfare $d S(\widehat{c}) / d \widehat{c}$, evaluated at the equilibrium $c^{*}$. Together with (11) follows

$$
\left.\frac{d S(\widehat{c})}{d \widehat{c}}\right|_{\widehat{c}=c^{*}}=\left.\frac{d V(\widehat{c})}{d \widehat{c}}\right|_{\widehat{c}=c^{*}} \cdot x\left(c^{*}\right)+\left.\int_{0}^{c^{*}} \frac{\partial R(c, \widehat{c})}{\partial \widehat{c}}\right|_{\widehat{c}=c^{*}} \cdot f(c) d c>0 .
$$

At the Nash equilibrium $c^{*}$, social welfare is not maximized. We have $c^{* *}>c^{*}$ due to (17). Hence, $x\left(c^{* *}\right)<x\left(c^{*}\right)$, the proportion of agents without prevention is higher in the Nash equilibrium than in the welfare optimum. As a result, the indirect risk in the economy is "too high" from a social planner's viewpoint.

Thus, we have shown that the social level of loss prevention in a situation without insurance is "too low" from a social welfare point of view. This result is wellknown in public economics: in an economy with externalities, the equilibrium outcome is generally inefficient, i.e., the agents invest too little in prevention relative to the socially efficient level.

Introducing compulsory insurance, a monopolistic insurer may act as a social planner and in this way increase the social prevention level by setting appropriate prevention incentives using insurance premiums. With reference to our introductory examples, we may consider terrorism insurance in the case of aircraft security, loss of profits insurance (business interruption insurance) in the case of internet risks, health insurance in case of smokers, and liability insurance, respectively. This issue is studied in the next section.

\section{Compulsory insurance monopoly}

Consider a risk-neutral monopolistic insurer with no transaction costs. Insurance is compulsory, thus there is full market participation and coverage is provided to all agents. Let us assume that insurance premiums are subject to public regulation in the sense that the expected profits of the monopolist are limited (for example by government) to some constant $k \geq 0$. $^{24}$

\footnotetext{
23 Note that at $c^{* *}$ there is indeed a maximum since $d S(\widehat{c}) / d \widehat{c}$ is positive at $\widehat{c}=0$ and negative at $\widehat{c}=L$.

24 This assumption is necessary to limit the insurer's profit to a maximum. If we assumed profit maximization for the insurer, it would - as a consequence of compulsory insurance-demand infinitely high premiums. The results of our model would then be implausible. Thus a restriction is needed here. Note that this restriction has some empirical justification in Switzerland: the property insurance monopolies in the Swiss cantons are under public control and earn a low or zero rate of return. See Jametti and Ungern-Sternberg [2005, p. 27]. Note also that there might be an incentive for the monopolist to behave inefficiently. However, there seems to be no empirical evidence which might support this hypothesis. Therefore, we do not analyze the insurer's incentive problem in more detail.
} 
By concluding insurance contracts, agents substitute their expected uncertain loss-expenses for the payment of a certain insurance premium. An insurance policy $(P, I)$ consists of a premium paid by an agent regardless of state $P$ and an indemnification payment $I$ in case of loss. Without loss of generality, we assume that losses are completely reimbursed after an accident occurs, i.e., there is no risk sharing between the insurer and its customers. Thus the indemnification payment $I$ in case of loss equals $L$. For the time being, we suppose that the monopolist offers an actuarially fair price, so the premium equals the individual expected loss of a policyholder (i.e., the expected loss with and without an investment in loss prevention, respectively). We therefore begin the analysis, as a point of reference, by assuming zero expected profits of the monopolist $(k=0){ }^{25}$

The policyholders can be divided into two groups: "low cost" agents who tend to invest in loss prevention and "high cost" agents who don't. While the insurer cannot, in general, observe individual prevention cost, it may, however, assign fair premiums to policyholders when it has information about the social prevention level and to which group a policyholder belongs. Suppose that the insurer can neither observe individual prevention cost nor an individual investment in prevention. It has, however, an idea about the distribution of costs in the economy. We make the reasonable assumption that the agents voluntarily provide evidence of their preventive measures to the insurer in order to get the lower (fair) premium based on their lower risk. Assuming further that risk revelation imposes no additional cost to a policyholder, an agent with "low cost" and for whom prevention is worthwhile has indeed an incentive to truthfully reveal himself as being a "good risk." 26 In addition, the insurer can easily determine the cost of the marginal agent and therefore the social prevention level; it does not need any information about individual prevention costs (i.e., in the following, from (20) follows directly (23)).

Given a social prevention level $\widehat{c}$, let the fair premium of an agent not investing in prevention be $P_{0}(\widehat{c})=\{p+(1-p) q(\widehat{c})\} L$ and for an agent investing in prevention $P(\widehat{c})=q(\widehat{c}) L{ }^{27}$ Then the expected utility of an agent who does not invest in prevention is (under full insurance coverage, i.e., $I=L$ ):

$$
\begin{gathered}
p U\left(W-L+I-P_{0}(\widehat{c})\right)+(1-p)\{q(\widehat{c}) . \\
\left.U\left(W-L+I-P_{0}(\widehat{c})\right)+(1-q(\widehat{c})) U\left(W-P_{0}(\widehat{c})\right)\right\} \\
=U\left(W-P_{0}(\widehat{c})\right),
\end{gathered}
$$

while the expected utility of an agent who invests in prevention is given by

\footnotetext{
25 This assumption is only by notational convenience and without any loss of generality. Constraining the monopoly profit to be an arbitrary value (including a general margin or premium loading) rather than zero has no qualitative impact on the results in this section or throughout the paper. We refrain from introducing a general margin since this is not an issue in our model.

26 Alternatively, it might be assumed that the insurer can costlessly observe whether an agent invests in loss prevention, but cannot observe individual prevention cost. The insurer is unable to distinguish between agents except through their choices.

27 Without prevention, the probability of loss given a social prevention level of $\widehat{c}$ is $\{p+(1-p) q(\widehat{c})\}$. With prevention, this probability is reduced to $q(\widehat{c})$. See $(6)$ and (7), respectively.
} 
$q(\widehat{c}) U(W-L+I-c-P(\widehat{c}))+(1-q(\widehat{c})) U(W-c-P(\widehat{c}))=U(W-c-P(\widehat{c}))$.

An individual investment in loss prevention is attractive to an agent if

$$
\Phi(c, \widehat{c})=U(W-c-P(\widehat{c}))-U\left(W-P_{0}(\widehat{c})\right) \geq 0 .
$$

Let again $\Phi(\widehat{c}, \widehat{c}) \equiv \Phi(\widehat{c})$, then along with $0 \leq q(\widehat{c}) \leq \bar{q}<1$, it follows that

(1) at position $\widehat{c}=0$

$$
\Phi(0)=U(W-\bar{q} L)-U(W-p L-(1-p) \bar{q} L)>0
$$

(2) at position $\widehat{c}=L$

$$
\Phi(L)=U(W-L)-U(W-p L)<0,
$$

so that $\Phi(\widehat{c})$ has an interior solution $c^{I^{*}}$ at $\Phi\left(c^{I *}\right)=0$, where $0<c^{I *}<L$. Thus we have

$$
c^{I *}=p\left(1-q\left(c^{I *}\right)\right) L
$$

$c^{I^{*}}$ is the Nash equilibrium with insurance at actuarially fair premiums. ${ }^{28}$ At the equilibrium $c^{I^{*}}$, the fair premium for agents investing in prevention is given by $P\left(c^{I *}\right)=q\left(c^{I *}\right) L$ and for agents not investing is $P_{0}\left(c^{I *}\right)=\left\{p+(1-p) q\left(c^{I *}\right)\right\} L$, respectively, corresponding to individual expected loss with and without an investment in loss prevention.

Social welfare is given by

$$
\widetilde{S}(\widehat{c})=\int_{0}^{c} U(W-c-P(\widehat{c})) f(c) d c+U\left(W-P_{0}(\widehat{c})\right) \cdot x(\widehat{c}) .
$$

Keeping in mind that $d x(\widehat{c}) / d \widehat{c}=-f(\widehat{c})$, the first-order condition for an interior maximum of $\widetilde{S}(\widehat{c})$ implies

$$
\begin{gathered}
\frac{d \widetilde{S}(\widehat{c})}{d \widehat{c}}=\left\{U(W-\widehat{c}-P(\widehat{c}))-U\left(W-P_{0}(\widehat{c})\right)\right\} \cdot f(\widehat{c}) \\
+\frac{d U\left(W-P_{0}(\widehat{c})\right)}{d \widehat{c}} x(\widehat{c})+\int_{0}^{\widehat{c}} \frac{\partial U(W-c-P(\widehat{c}))}{\partial \widehat{c}} f(c) d c=0 .
\end{gathered}
$$

Thus $\widetilde{S}(\widehat{c})$ has an interior maximum at $c^{I * *}$ so that

\footnotetext{
${ }^{28}$ Comparing $c^{I *}$ to $c^{*}$, observe that the equilibrium $c^{*}$ includes some risk premium. This is due to the risk aversion of the agents. Being now fully compensated in case of loss, the completely insured agents act as if they were risk neutral. Therefore, no risk premium appears in the equilibrium $c^{I^{*}}$. Indeed, the Nash equilibrium is actually the same as with risk neutral policyholders.
} 


$$
c^{I * *}=\arg \max _{\widehat{c}} \widetilde{S}(\widehat{c}) .
$$

$c^{I * *}$ is the socially optimal prevention level with insurance. ${ }^{29}$ Again, at position $c^{l^{*}}$, we obtain

$$
\begin{aligned}
& \left.\frac{d \widetilde{S}(\widehat{c})}{d \widehat{c}}\right|_{\widehat{c}=c^{l *}}=\left.\frac{d U\left(W-P_{0}(\widehat{c})\right)}{d \widehat{c}}\right|_{\widehat{c}=c^{l *}} \cdot x\left(c^{I *}\right) \\
& +\left.\int_{0}^{c^{l *}} \frac{\partial U(W-c-P(\widehat{c}))}{\partial \widehat{c}}\right|_{\widehat{c}=c^{l *}} \cdot f(c) d c>0 .
\end{aligned}
$$

Hence $c^{I *}<c^{I * *}$ results. This implies that $x\left(c^{I *}\right)>x\left(c^{I * *}\right)$, the proportion of agents without prevention is higher in the Nash equilibrium than in the welfare optimum. Clearly, given insurance is available at fair premiums, the social prevention level is not optimal. Again, externalities are not internalized in the Nash equilibrium.

The insurer may engage in premium discrimination in order to raise the social prevention level. In particular, it may design different contracts for different risk types, relying on the policyholders' self-categorization: it may offer a premium rebate-relative to the fair premium-for low risk agents (i.e., those investing in prevention), and/or it may impose a premium loading for high risk agents (i.e., those not investing in prevention), and let agents voluntarily decide whether or not to invest in loss prevention. The sequence of the considered game between the insurer and its customers may then be seen as follows. At a first stage, the insurer offers appropriate contracts including a premium loading and rebate on fair premiums. At a second stage, the customers choose a contract and decide simultaneously on the basis of their individual cost whether or not to invest in prevention.

The insurer may act like a social planner by demanding premiums that do not only depend on the actuarial value of the policy, i.e., the expected loss, but depend also on the "prevention behavior" of the agents. In this way, the social prevention level would rise and individual expected loss of each agent would decrease. For this reason, risk categorization may increase allocative efficiency.

In the following, we will show that the monopolist may shift the social prevention level in the economy up to the optimal level by engaging in premium discrimination. Completely insured agents act like risk neutral decision makers. Therefore, since our focus is on optimal risk allocation, the expected utility of agents with and without an investment in prevention is given by $W-c-P(\widehat{c})$ and $W-P_{0}(\widehat{c})$, respectively.

For agents who do not invest in prevention, the insurer may offer a premium $P_{0}(\widehat{c})+\gamma$, where $\gamma>0$ denotes a premium penalty (loading). For agents who invest in prevention, it may offer a premium $P(\widehat{c})-\delta$, where $\delta>0$ denotes a premium rebate. We will argue in the following that the insurer may achieve the socially optimal prevention level in the economy by offering a combination of rebates and

\footnotetext{
${ }^{29}$ Again, note that at $c^{I * *}$ there is indeed a maximum since $d \widetilde{S}(\widehat{c}) / d \widehat{c}$ is positive at $\widehat{c}=0$ and negative at $\widehat{c}=L$.
} 
penalties on fair premiums, and at the same time make non-negative expected profits $k \geq 0$. Hence, the insurer engages in premium discrimination so that the agents individually place themselves into one of two categories: those who invest in prevention and those who don't. This result is shown in the following Proposition.

Proposition The insurer can induce the socially optimal prevention level $c^{\text {I** }}$ by engaging in premium discrimination: it can charge a premium penalty $\gamma^{*}$ on fair premiums for agents who do not invest in prevention and offer a premium rebate $\delta^{*}$ on fair premiums for agents who do. The optimum is induced by setting $\hat{c}=c^{I * *}$ for premiums.

Proof The marginal agent is indifferent between prevention and no prevention if

$$
W-\hat{c}-\{P(\widehat{c})-\delta\}=W-\left\{P_{0}(\widehat{c})+\gamma\right\} .
$$

Let us refer to (28) as the incentive constraint. Assuming further that the insurer tries to achieve the maximum-permitted profit $k \geq 0$, an optimal premium discrimination mechanism must ensure that the expected profit of the insurer equals $k$. Therefore, we must have

$$
\gamma \cdot x(\hat{c})-\delta \cdot\{1-x(\hat{c})\}=k \geq 0 .
$$

Let us refer to (29) as the participation constraint. ${ }^{30}$ Social welfare is given by the "sum" of expected utilities of all agents in the economy and the expected profit of the monopolist:

$$
\widetilde{S}(\delta, \gamma, \widehat{c})=\int_{0}^{\widehat{c}}\{W-c-(P(\widehat{c})-\delta)\} f(c) d c+\left\{W-\left(P_{0}(\widehat{c})+\gamma\right)\right\} \cdot x(\widehat{c})+k
$$

We can rewrite (30), by using (29), to read $^{31}$

$$
\widetilde{S}(\widehat{c})=\int_{0}^{\widehat{c}}\{W-c-P(\widehat{c})\} f(c) d c+\left\{W-P_{0}(\widehat{c})\right\} \cdot x(\widehat{c}) .
$$

The incentive constraint (28) together with the participation constraint (29) becomes

$$
p(1-q(\widehat{c})) L-\widehat{c}+\frac{\gamma}{1-x(\widehat{c})}-\frac{k}{1-x(\widehat{c})}=0 .
$$

We write the Lagrangian function, subject to (32), to read

\footnotetext{
30 The participation constraint states that the insurer should make non-negative expected profits because otherwise it would not be interested in premium discrimination. Without loss of generality, we may assume that the insurer has still an incentive to engage in premium discrimination when its expected profits are zero.

${ }^{31}$ Note that $\int_{0}^{\widehat{c}} \delta f(c) d c-\gamma x(\widehat{c})=\delta(1-x(\widehat{c}))-\gamma x(\widehat{c})=-k$.
} 


$$
\begin{aligned}
\mathcal{L}(\gamma, \widehat{c}, \lambda)= & \int_{0}^{\widehat{c}}\{W-c-P(\widehat{c})\} f(c) d c+\left\{W-P_{0}(\widehat{c})\right\} \cdot x(\widehat{c}) \\
& +\lambda\left\{p(1-q(\widehat{c})) L-\widehat{c}+\frac{\gamma}{1-x(\widehat{c})}-\frac{k}{1-x(\widehat{c})}\right\},
\end{aligned}
$$

where $\lambda$ indicates the Lagrange-multiplier. A necessary first-order condition for a maximum of $\mathcal{L}$ is

$$
\frac{\partial \mathcal{L}(\gamma, \widehat{c}, \lambda)}{\partial \gamma}=\lambda \cdot\left\{\frac{1}{1-x(\widehat{c})}\right\}=0
$$

Since the term in braces is positive for any $\widehat{c}>0, \lambda=0$ results. Therefore, (33) is reduced to (31), which is at its maximum at $c^{I * *}$. Hence, the optimal value for the cutoff level is $\hat{c}=c^{I * *}$. $^{32}$

It can be shown in the same way that the socially optimal prevention level is achievable by imposing a premium loading $\widetilde{\gamma}$ on fair premiums for high risk agents (those who do not invest in prevention) and by insuring low risk agents (those who do) at their fair premium. Theoretically, the optimum may also be induced by offering a premium rebate $\widetilde{\delta}$ for low risk agents and by insuring high risk agents at their fair premium. However, a rebate is not a plausible solution to the externality problem since it implies negative expected profits for the insurer, i.e., the participation constraint is not fulfilled.

The social optimum can also be induced in a setting where low risk agents pay a zero premium and high risk agents pay a high loading. The idea behind this setting is that the insurer may set prices according to causation. Then the "originators" (high risk agents) are made fully responsible for the externalities caused by them. In this special case, the damaged parties (i.e., low risk agents who would not suffer any loss if not for those high risk agents) would pay zero premiums.

The previous proposition demonstrates that the insurer may shift the social prevention level up to the optimum and thereby ensure an efficient risk allocation in the economy. This outcome is shown under very general conditions, since constraining the monopoly profit to be equal to some constant $k$ rather than zero has no qualitative impact on the results.

\section{Discussion and conclusion}

Casual observation suggests that an agent's decision to self-protect often affects the loss probabilities faced by others. As well-known in public economics, when externalities are present the equilibrium outcome will be inefficient. In an economy with interdependent risks, this result implies that economic agents invest too little in

$\overline{32} \delta^{*}=\left\{c^{I * *}-p\left(1-q\left(c^{I * *}\right)\right) L\right\} x\left(c^{I * *}\right)-k$ and $\gamma^{*}=c^{I * *}-p\left(1-q\left(c^{I * *}\right)\right) L-\delta^{*}$ result. This is due to (28) and (29). Since the premium rebate for agents investing in prevention $\delta^{*}$ should not exceed the fair premium $\left(P\left(c^{I * *}\right)-\delta^{*} \geq 0\right)$, the profit of the monopolist should meet a minimum $k \geq\left\{c^{I * *}-p\left(1-q\left(c^{I * *}\right)\right) L\right\} x\left(c^{I * *}\right)-q\left(c^{I * *}\right) L . \square$ 
loss prevention relative to the socially efficient level by ignoring marginal external costs or benefits conferred on others. Given interdependent risks in an insurance market, this paper examines the possibility that the social prevention level is improved by a monopolistic insurer engaging in premium discrimination.

The paper makes two contributions to the insurance literature. First, it analyzes an insurance market with externalities of loss prevention in a model with multiple heterogeneous risk-averse agents. When risks are interdependent, the social prevention level-both in case of no insurance and with (compulsory) insurance at actuarially fair premiums - is not socially efficient. The indirect risk in the economy is too high from a social planner's viewpoint. However, a monopolistic insurer with imperfect information may achieve the optimum by engaging in premium discrimination. Premiums are optimally chosen to reflect social cost or benefit. For instance, an agent who invests in loss prevention may enjoy a premium rebate not only for the reduced individual expected loss, but also for the reduction in expected loss to others. The insurer designs different contracts for different risk types, relying on the agents' incentives to self-protect.

The second contribution is a theoretical explanation of empirical findings. The social prevention level in markets with (compulsory) insurance monopolies tends to be substantially higher (and therefore the claims levels tend to be lower) than in competitive insurance markets. An inefficient outcome may result because in competitive insurance markets with interdependent risks, no allocative efficiency seems to be attainable, whether insurance is compulsory or not. The rationale for the latter is as follows. Suppose a market with many risk neutral insurers being in competition to attract customers, and suppose insurers act so as to maximize expected profits. The only policies that will survive in the market are those that yield zero expected profits to insurers and, given this constraint, the highest possible expected utility to agents. Arbitrarily risk-averse agents will buy full insurance coverage if the price of insurance is actuarially fair. ${ }^{33}$ As a consequence, full insurance at fair premiums results and the competitive Nash equilibrium corresponds to $c^{I^{*}}$. However, we have shown that in an environment involving externalities of loss prevention, social welfare is not optimal at $c^{I^{*}}$. Due to the possibility of adverse selection in this market, an insurer acting in a competitive market environment cannot induce high risk agents to pay a premium loading, i.e., other insurers may undercut the demanded price by ignoring externalities. The only premium for which there is no incentive to undercut a rival firm is the fair premium. As a result, externalities cannot be internalized in a competitive insurance market.

A further intuitive argument is that in a competitive insurance market, when an insurer undertakes actions that reduce the riskiness of its policyholders (i.e., engaging in premium discrimination), it will run the risk of competing insurers free-riding on its achievements in reducing the risks. Therefore, an insurer acting in a competitive insurance market will have little or no incentive

\footnotetext{
33 See, for instance, Arrow [1963], Mossin [1968], Smith [1968] or Doherty [1975].
} 
(compared to the monopolist) to engage in premium discrimination, given that competitors may enjoy the benefits at no cost. Hence, there seems to be a strong argument for a monopolistic insurer in an insurance market with interdependent risks.

Regarding the roles of insurance coverage and premiums, our model is not rich enough to allow agents to choose partial insurance coverage. However, full insurance would be chosen if premiums were actuarially fair, and so the Nash equilibrium with insurance at fair premiums derived here would also hold in that case. Since the premiums in our model are marginally fair, i.e., include a fixed loading fee (or rebate), full insurance is optimal. ${ }^{34}$ Hence, the assumption of full insurance coverage does not restrict the analysis, but simplifies it.

The model might be extended in the following ways. The probability of a direct loss $p$ was taken as constant among policyholders. This assumption is undoubtedly very restrictive, but it is for simplicity reasons only. Since $p$ only affects the individual expected loss and not the indirect risk in the economy (given the assumptions above), agents differing in both $p$ and $c$ might be integrated in the analysis without changing results substantially. In fact, the externality is independent of $p$ and would therefore not be affected by this generalization of the model.

Also, loss prevention has been modeled as a discrete choice, i.e., an agent can either invest in loss prevention or not. An extension to a setting where loss prevention is a continuous variable would change the results as follows. If loss prevention is continuous, agents who invest in prevention-those who did not impose any externality on others in our model-will then impose some externality on others, too, given that the probability $p$ cannot (always) be reduced to zero. In our model, some agents - those with prevention costs higher than the Nash equilibrium but lower than the social optimum-do not behave efficiently, while the others do. In a model with continuous loss prevention, however, all agents will undertake less than optimal prevention since they do not take into account the social benefit of their individual prevention effort. Therefore, the equilibrium prevention level will be inefficient. When the insurer has full information, it might set premiums according to individual efforts, and might in this way achieve the social optimum.

An alternative instrument to internalize externalities of loss prevention is liability law. Liability requirements tend to improve the agents' incentives to reduce risks. An optimal liability rule sets incentives for efficient loss prevention (care). Common liability rules in economic theory of liability law are strict liability and the negligence rule. Under strict liability injurers must pay for all losses that they cause. Under the negligence rule an injurer is held liable for losses he causes only he if was negligent, i.e., only if his level of care is less than a level specified by courts, the level of due care. Generally, when the probability of loss depends on preventive efforts of both injurer and victim, the negligence rule is optimal when the level of due care is set equal to the socially efficient level. In contrast, in this case, strict

\footnotetext{
34 Note that this outcome includes the implicit assumption that a contract with partial insurance is calculated so as to fully internalize the externality.
} 
liability is not optimal since there is no incentive for the victim to behave efficiently. ${ }^{35}$ In our model, however, only the injurer is able to reduce the probability of loss (i.e., we analyze the case of unilateral losses). Therefore, the socially efficient level of care may be induced via strict liability as well, since a potential injurer would in any case internalize the entire liability risk. As a result, strict liability and the negligence rule are equivalent.

It should be observed that liability rules are generally studied in a setting with risk neutral agents. In a setting with risk-averse agents, however, strict liability might not be optimal any more. As our introductory examples suggest, in a world with interdependent risks, an injurer might often cause losses to many victims, and thus strict liability might lead to a risk accumulation while the negligence rule spreads the risk. ${ }^{36}$ So the negligence rule seems to be better in terms of risk allocation due to the possibility of many victims.

Nevertheless, liability law may not work any more in order to internalize externalities of loss prevention when the injurer cannot be identified. In a setting with interdependent risks, loss prevention generally spreads and the actual injurer may not (easily) be found. As a result, liability law is indeed an alternative instrument in order to internalize externalities of loss prevention, but under more general conditions involving information problems, there might be situations where it seems more reasonable to internalize prevention externalities ex ante (before a loss actually takes place) via insurance premiums, and not ex post (after a loss has occurred) via liability law where the injurer has to be identified. A monopoly insurer may overcome such information problems.

Clearly, in a competitive insurance market, insurance regulation may solve the externality problem, as well. A regulator may offer a tax cut on insurance contracts for low risks and impose higher tax rates for high risks. Regulation would then provide the same incentives in the insurance market as an insurance monopoly engaging in premium discrimination. However, an insurer will generally be better informed about prevention costs, risk aversion and loss probabilities of its policyholders than a regulator. It might be socially desirable to implement a monopoly insurer to solve this task by regulating only the insurer's expected profit.

Finally, the efficiency gain of price discrimination by the insurer should be weighted against disadvantages that are generally associated with monopolies. Since a monopolist is not forced by competitive threat to operate at lowest cost, it may not be as productively efficient as an insurer in a competitive insurance market. Furthermore, it may not have the same innovation incentive and therefore may not want to reduce costs in the same way. Given that innovation seems to play an important role in some lines of insurance only, these shortcomings seem not so important in insurance markets when compared to other markets.

Note also that the analysis includes some equity efficiency trade-off: it may not be the case that all agents in the insurance market are better off after the introduction of premium discrimination. This generally depends on the parameters in the model and the distribution of prevention costs. However, the possibility of an

\footnotetext{
${ }^{35}$ We restrict our discussion to the pure forms of strict liability and the negligence rule here.

36 See, for instance, Nell and Richter [2003, p. 32].
} 
internalization of externalities necessarily implies such sort of trade-off. The efficiency will always be improved in the sense of Kaldor-Hicks efficiency, but not necessarily in the sense of Pareto efficiency. Thus, a more efficient outcome might in fact leave some agents worse off. Therefore, losses in equity due to premium discrimination need to be weighted against the social costs of the market failure that it seeks to overcome. Generally, the potential efficiency gain of an insurance monopoly relative to a competitive insurance market will depend on the magnitude of externalities in the market considered. Thus, the more important externalities in the market are, the more an insurance monopoly seems to make sense.

Acknowledgments The author thanks Pierre Picard, an anonymous referee, and Martin Nell, whose comments and suggestions have led to significant improvements in the paper. I am also grateful to participants in the American Risk and Insurance Association Annual Meeting in Washington, August 2006, as well as in the 33rd Seminar of the European Group of Risk and Insurance Economists in Barcelona, September 2006, for valuable discussions.

\section{References}

ARNOTT, R. and STIGLITZ, J.E. [1986]: "Moral Hazard and Optimal Commodity Taxation,” Journal of Public Economics, 29, 1-24.

ARROW, K.J. [1963]: "Uncertainty and the Welfare Economics of Medical Care," American Economic Review, 53, 941-973.

AVERY, C., HEYMANN, S.J., and ZECKHAUSER, R. [1995]: "Risks to Selves, Risks to Others," American Economic Review, 85, 61-66.

BOND, E.W. and CROCKER, K.J. [1991]: "Smoking, Skydiving, and Knitting: The Endogenous Categorization of Risks in Insurance Markets with Asymmetric Information," Journal of Political Economy, 99, 177-200.

BRITO, D., SHESHINSKI, E., and INTRILIGATOR, M.D. [1991]: "Externalities and Compulsory Vaccinations," Journal of Public Economics, 45, 69-90.

COASE, R.H. [1960]: “The Problem of Social Cost," Journal of Law and Economics, 3, 1-44.

DOHERTY, N.A. [1975]: "Some Fundamental Theorems of Risk Management," Journal of Risk and Insurance, 42, 447-460.

EHRLICH, I. and BECKER, G.S. [1972]: "Market Insurance, Self-Insurance, and Self-Protection," Journal of Political Economy, 80, 623-648.

EPPLE, K. and SCHÄFER, R. [1996]: "The Transition from Monopoly to Competition: The Case of Housing Insurance in Baden-Wü rttemberg," European Economic Review, 40, 1123-1131.

FELDER, S. [1996]: "Fire Insurance in Germany: A Comparison of Price-Performance between State Monopolies and Competitive Regions," European Economic Review, 40, 1133-1141.

GIFFORD, A. and STONE, C. [1973]: "Externalities, Liability and the Coase Theorem: A Mathematical Analysis," Western Economic Journal, 11, 260-269.

HEAL, G. and KUNREUTHER, H.C. [2004]: Interdependent Security: A General Model. NBER Working Paper No. W10706.

JAMETTI, M. and UNGERN-STERNBERG, T.V. [2005]: "Assessing the Efficiency of an Insurance Provider-A Measurement Error Approach," Geneva Risk and Insurance Review, 30, 15-34.

KAPLOW, L. [1991]: "Incentives and Government Relief for Risk," Journal of Risk and Uncertainty, 4, $167-175$.

KEARNS, M. [2005]: "Economics, Computer Science, and Policy,” Issues in Science and Technology, $21,37-47$.

KUNREUTHER, H.C. and HEAL, G. [2002]: Interdependent Security: The Case of Identical Agents. NBER Working Paper No. W8871.

KUNREUTHER, H.C. and HEAL, G. [2003]: “Interdependent Security," Journal of Risk and Uncertainty (Special Issue on the Risks of Terrorism), 26, 231-249. 
LEE, K. [2005]: "Wealth Effects on Self-Insurance and Self-Protection against Monetary and Nonmonetary Losses," Geneva Risk and Insurance Review, 30, 147-159.

MIRRLEES, J. [1971]: “An Exploration of the Theory of Optimal Taxation," Review of Economic Studies, 38, 175-208.

MOSSIN, J. [1968]: “Aspects of Rational Insurance Purchasing,” Journal of Political Economy, 76, 553568.

NELL, M. and RICHTER, A. [2003]: “The Design of Liability Rules for Highly Risky Activities-Is Strict Liability Superior when Risk Allocation Matters?," International Review of Law and Economics, 23, 31-47.

PRATT, J.W. [1964]: "Risk Aversion in the Small and in the Large," Econometrica, 32, 122-136.

SCHLESINGER, H. and VENEZIAN, E. [1986]: "Insurance Markets with Loss-Prevention Activity: Profits, Market Structure, and Consumer Welfare," RAND Journal of Economics, 17, 227-238.

SHAVELL, S. [1979]: “On Moral Hazard and Insurance," Quarterly Journal of Economics, 93, 541-562.

SHAVELL, S. [1982]: “On Liability and Insurance,” Bell Journal of Economics, 13, 120-132.

SMITH, V.L. [1968]: “Optimal Insurance Coverage,” Journal of Political Economy, 76, 68-77.

UNGERN-STERNBERG, T.V. [1996]: "The Limits of Competition: Housing Insurance in Switzerland," European Economic Review, 40, 1111-1121.

UNGERN-STERNBERG, T.V. [2003]: State Intervention on the Market for Natural Damage Insurance in Europe. CESifo Working Paper 1067.

UNGERN-STERNBERG, T.V. [2004]: Efficient Monopolies-The Limits of Competition in the European Property Insurance Market, Oxford University Press: New York, USA. 